\title{
Genetic models of structural traps related to normal faults in the Putaohua Oilfield, Songliao Basin
}

\author{
Sun Simin $^{1}{ }^{*}$, Wu Xinsong ${ }^{1}$, Liu Hongtao ${ }^{2}$ and Wang Changsheng ${ }^{2}$ \\ ${ }^{1}$ School of Resources and Information Technology, China University of Petroleum, Beijing 102249, China \\ ${ }^{2}$ Oil Recovery Plant No.7, Daqing Oilfield Company, PetroChina, Daqing, Heilongjiang 163517, China
}

\begin{abstract}
The Putaohua Oilfield is a fault-prolific area and the faults have close relation with structural traps. The genetic models of the structural traps in the Putaohua Oilfield can be divided into two types: individual fault model and multi-fault interaction model. This is based on the description of displacement distribution of typical individual normal faults, the geometry of the footwall and hanging wall, and the analysis of the interaction between faults and the corresponding change in geometry when the faults grow. The individual fault model is that the displacement reaches a maximum at or near the center of fault and decreases toward the fault tips, so a half-graben is formed on the hanging wall of the fault and a halfanticline is formed on the footwall because of the isostatic process. The multi-fault interaction model is that during the growth of faults, they overlap and interact with each other, and accommodation zones are formed in the overlapping segments. The accommodation zones are favorable targets for hydrocarbon exploration, and the trap characteristics are dependent on the extent of overlap and occurrence of faults. The multi-fault interaction model can be subdivided into three types: synthetic accommodation zone, convergent accommodation zone and divergent accommodation zone. Hydrocarbon migration and accumulation models of each type have been developed. The hydrocarbon migration and accumulation models of the traps with different genetic models have their own characteristics in the different stages of fault growth.
\end{abstract}

Key words: Songliao Basin, Putaohua Oilfield, accommodation zone, normal fault growth, structural trap

\section{Introduction}

Structural traps are closely tied to normal faults in extensional basins. Many geologists have presented several genetic models of structural traps related to normal faults. However, their researches were primarily on the characteristics of fault surface orthogonal to strike (Shelton, 1984; Dula, 1991; Xiao and Suppe, 1992) or fault-blocks due to fault intersecting (Wang et al, 1994; Li, 2004; Wang, 1995; Xie et al, 1997). In recent years, great advances have been made in the geometry and kinematics of normal faults based on the research on the East Africa Rift, Viking Graben of North Sea and the Basin and Range Province in the United States (Rosendahl, 1987; Scott and Rosendahl, 1989; Morley et al, 1990; Faulds and Varga, 1998; Varga et al, 2004). The influence of variations of fault characteristics along the strike on the basin pattern has been noticed and the concepts, types and genetic models of normal fault growth and accommodation zone have been presented, which are very helpful in the development of structural analysis from 2D to $3 \mathrm{D}$. The researches show that the length and displacement of faults are closely related to each other. When normal faults grow laterally (displacement increases), they approach,

*Corresponding author. email: sunsimin@gmail.com

Received March 21, 2008 overlap and interact with other faults and then form a variety of accommodation zones and structural traps (Morley et al, 1990; Faulds and Varga, 1998; Anders and Schlische, 1994; Cowie and Scholz, 1992).

In the study area of this paper, a great number of faults and related structural traps have been found because of new 3D seismic acquisition in 2006 covering the whole oilfield and fine interpretation. It is proven that faults apparently dominate the local accumulation of hydrocarbon. Though almost all the proven structural traps are fault-related, there is no clear genetic relation acquired between them for a long time, especially between a large number of small newlyfound faults and structural traps. This paper tries to construct genetic models of structural traps related to normal faults, hydrocarbon migration and accumulation models and their relations with normal fault growth and accommodation zones based on the accurate description of structural features by 3D seismic data. They are instructive for future hydrocarbon exploration and development in this oilfield.

\section{Geological background}

Located in the northeast of China, the Songliao Basin is a large Mesozoic-Cenozoic non-marine sedimentary basin, with an area of approximately $260,000 \mathrm{~km}^{2}$. The Cretaceous system is the main hydrocarbon-bearing formation, with a 
thickness greater than $5,000 \mathrm{~m}$. The geologic evolution of the basin experienced the early rift process in the Jurassic and terrigenous clastic sedimentation during the depression process in the Cretaceous. The Putaohua Oilfield is located in the south of the Daqing placeanticline, and is a mild anticline whose axial direction is northeast $25^{\circ}, 46 \mathrm{~km}$ long and $23 \mathrm{~km}$ wide, with an approximate area of $570 \mathrm{~km}^{2}$ and a closure height of $307 \mathrm{~m}$ (Fig. 1). The main reservoir is the Putaohua reservoir in the Yaojia Formation of the Lower Cretaceous, and the source rock is underlying dark lacustrine thick shale of the Qingshankou Formation. The average thickness of a single sand body is $2 \mathrm{~m}$. A large number of faults are densely distributed in the oilfield and all of them are normal faults. The large faults usually connect with one another along the strike, and divide the oilfield into many fault-blocks trending north to south. Faults dominate the accumulation of hydrocarbon, thus the oil/water contact of each fault block is different from others. There are also a large number of small faults, which typically extend $500-2000 \mathrm{~m}$, with displacement of $10-50 \mathrm{~m}$ and dip of approximately $40^{\circ}-50^{\circ}$. Taking the south of the oilfield as an example, there are 427 faults distributed on the top of the Putaohua reservoir. The structural traps in the oilfield are related to faults. The Putaohua oilfield is an important one among many oilfields in north Songliao Basin. Through 28 years development, the Daqing Oilfield at present faces a serious shortage of newly-increased reserves and a rapid increase in water cut. Therefore, it is necessary to drill efficient wells and find new reserves both inside and outside the oilfield.

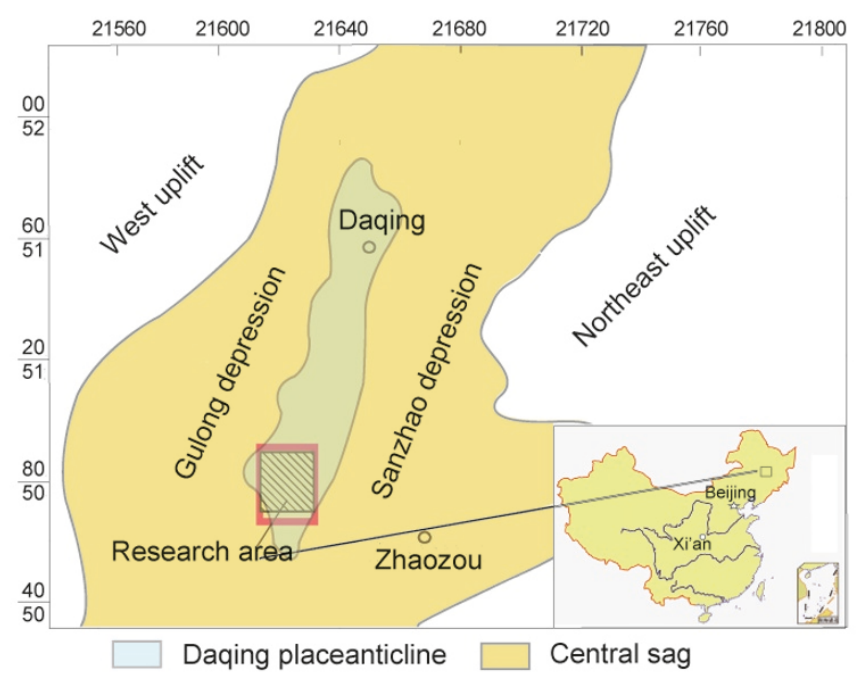

Fig. 1 Structural location of Putaohua Oilfield, Songliao Basin

\section{Growth model of normal faults}

Displacement on individual normal faults typically reaches a maximum at or near the middle of the faults and progressively decreases toward the tips. The subsidence of hanging wall also decreases in the direction vertical to the strike of the fault, so a half-graben is formed on the hanging wall (Faulds and Varga, 1998). Meanwhile, the subsidence of hanging wall results in the uplift of footwall (Faulds and Varga, 1998; Anders and Schlische, 1994; Densmore et al, $2005)$ because of the isostatic process. The influence of an isolated fault on topography can be illustrated in Fig. 2. It shows a half-graben on the hanging wall and an uplift (semianticline) on the footwall in a mild terrane. In addition to the characteristics of fault displacement, the overall length of a normal fault generally exhibits a relationship to the magnitude of displacement, $\mathrm{D}=\mathrm{cL}$, where $\mathrm{D}$ is displacement, $\mathrm{L}$ is length, $\mathrm{c}$ is a constant related to rock properties, and $\mathrm{n}$ is an exponent (Soliva and Benedicto, 2005; Kim and Sanderson, 2005; Watterson, 1986; Walsh and Watterson, 1988). The size of the footwall uplift and the half-graben of hanging wall are also proportional to the length of the fault.

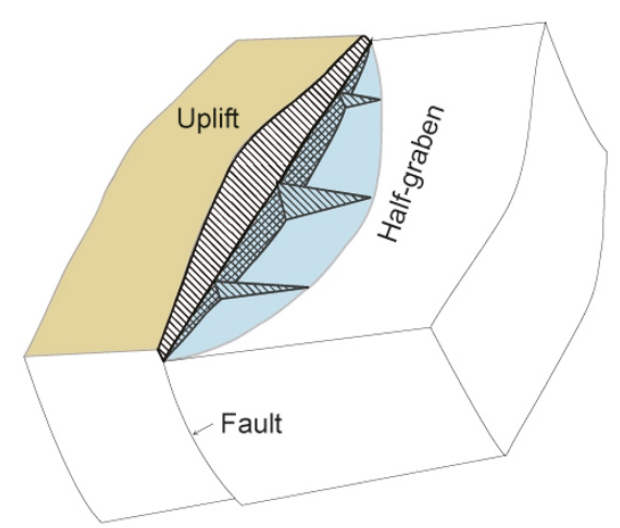

Fig. 2 Schematic diagram of the half-graben and uplift of a typical normal fault

What discussed above is an ideal model of an individual normal fault. Just as the D-L relationship, small faults grow into large faults over time, and thus result in the increase of length, width, and depth of hanging wall half-grabens or height of footwall uplifts. However, the situation can not continue all the time, since the original fault will approach, overlap and interact with other nearby faults over time. It is proven that large normal faults usually consist of multisegments and each segment shows the length-displacement pattern of an individual fault. It reveals the fact that large faults are formed by connection of several smaller faults while they grow. The evolution process is as follows: 1) Individual fault stage as mentioned above. 2) Segmented normal fault stage. Initially individual faults overlap, link and interact with others and each segment controls a halfgraben on its hanging wall, which resembles a simple basin bounded by an individual fault while at the joints of faults there are relatively intrabasin high points. 3) Linkage stage. Segmented faults link into a fault (system) which shows an uniform displacement distribution (Faulds and Varga, 1998; Anders and Schlische, 1994; Ford et al, 2007). In order to maintain the relationship between length and displacement of the fault system, the displacement must increase at the joints to compensate for the greatly increased length of fault system after the linkage. The intrabasin highs gradually become low or even disappear and the maximum subsidence of the hanging wall migrates to the center of the fault system. This 
is a complete evolution cycle of a large fault (system), and reveals the general regularities of fault development.

The local stress field of different faults interact at the zone of merger, and produce groups of structures known as accommodation (or transfer) zones, whose geometries are dependent on the extent of overlap, the scale and occurrence of faults (Morley et al, 1990; Faulds and Varga, 1998; Bonson et al, 2007). The accommodation zones are usually favorable structural trap development areas. Many faults in the study area show the characteristics of fault evolution of different stages. Normal faults approach, overlap and interact with others during their growth in the lateral and vertical directions, and consequently produce various structural traps.

\section{Genetic models of traps related to normal faults}

\subsection{Individual fault genetic model}

The structural map of this type is shown in Fig. 2. A halfgraben (or syncline) on the hanging wall and an uplift (semianticline) on the footwall. Many traps in the study area result from individual normal faults. Fig. 3 shows a typical instance. It can be seen that there are three small faults, A, B and C, which are about $500 \mathrm{~m}, 550 \mathrm{~m}$ and $700 \mathrm{~m}$ long respectively, and each controls a half-graben on its hanging wall, which is the local low, and a semi-anticline on its footwall, which is the local high. The semi-anticlines are obviously smaller than the half-grabens and the area and the height of uplifts or the extent of subsidence of half-grabens are related to the length of the faults. Semi-anticlines generally could not be found on the usual map with contour interval of $10 \mathrm{~m}$ for the small fault, such as A and B. It is proven by hydrocarbon production practice in this area that the small half-grabens are often highly water-flooded, and the uplifts on the hanging wall are favorable for the enrichment of remaining oil in the middle and late phases of oilfield development. Over 300 small faults with the length of approximately 500-1500m have been found in the study area by fine 3D seismic data interpretation, many of which coincide with the above fault model, but most are neglected on the usual map with contour interval of $10 \mathrm{~m}$ or more. Under the instruction of the trap model mentioned above, we plotted a structural map with a contour interval of $2-5 \mathrm{~m}$ to find the small traps (structural high) and locate the half-grabens (structural low), and successful wells were drilled on the semi-anticline of the footwall of the small faults. This method avoids the structural lows of the hanging wall, which are usually highly water-flooded and the fault surfaces, which often result in casing wear.

\subsection{Accommodation zone by fault interaction genetic model}

Originally individual normal faults interact and form accommodation zones, when they overlap and connect with each other as a result of lateral and vertical growth. They exhibit different types and features because of different occurrences and overlap extents of the faults. They are often favorable structural traps.

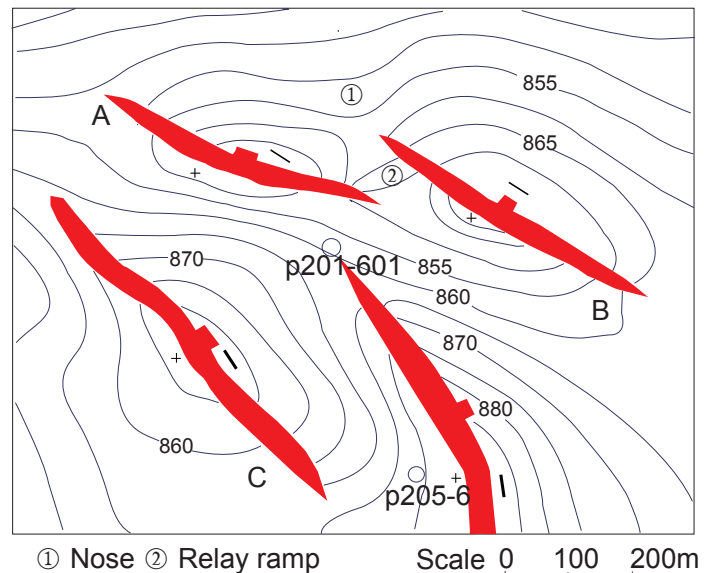

Fig. 3 Structural contour map top of Putaohua reservoir (Yaojia Formation). Normal fault A, B, and C show similar features to Fig. 2. Fault A and B overlap slightly, develop relay ramp and "nose" structure in or near the overlap areas

\subsubsection{Synthetic accommodation zone model}

Synthetic accommodation zones develop between normal faults with similar strike and dip when they approach, overlap and interact. There are two kinds of growth models. 1) Two collinear faults with each controlling a half-graben (similar to individual normal fault) grow laterally and connect together without strike variation at the fault tips (Fig. 6(a)). The newly connected fault consists of several segments and each exhibits similar displacement distribution to that of an individual fault. As a result, broken noses develop at the fault joints on the hanging wall while semi-anticlines are formed at the midsegments of the fault and structural lows at the joints on the footwall (Fig. 6(a)). Apparently, this situation happens at the beginning of fault linkage. Many traps in the study area belong to this kind. 2) Two parallel faults overlap when they grow laterally over time, and result in a relay ramp structure in the zone of overlap. Fig. 3 shows that relay ramps connect the hanging wall of one fault to the footwall of the other fault. It realizes the transition of footwall to hanging wall, and effectively transfer strain between two faults. There is also an apparent nose-like structure between two half-grabens on the hanging wall corresponding to the relay ramp. Minor oblique or transverse normal faults will develop on the relay ramp, which helps to produce fault-block traps if the two faults overlap further over time.

\subsubsection{Convergent accommodation zone model}

When two faults dip toward each other, the strata on the common hanging wall exhibit the "graben" features, and form an anticline. However, if each fault system consists of several faults with uniform dip, there will be great complexity. The accommodation zones are actually the superposition of synthetic accommodation zones and convergent accommodation zones, as shown in Fig. 4(a). Generally, an anticline belt develops between the two fault systems. The evolution process of this type is as follows (Fig. 4(b)): 1) Two groups of normal faults with similar dip keep no interaction in the direction both parallel and vertical to the strike. 2) Faults overlap along the strike and interact with 
each other at the zone of overlap; meanwhile they interact with the opposite faults of the other group, and produce a series of anticlines between them. The strike of faults obviously dominates that of the anticlines. In the study area, the strike of anticlines turns from NNE to NNW and then to NW following the faults. Apparently, it also helps to develop a variety of fault-block traps at the zone of overlap in the synthetic accommodation zone.

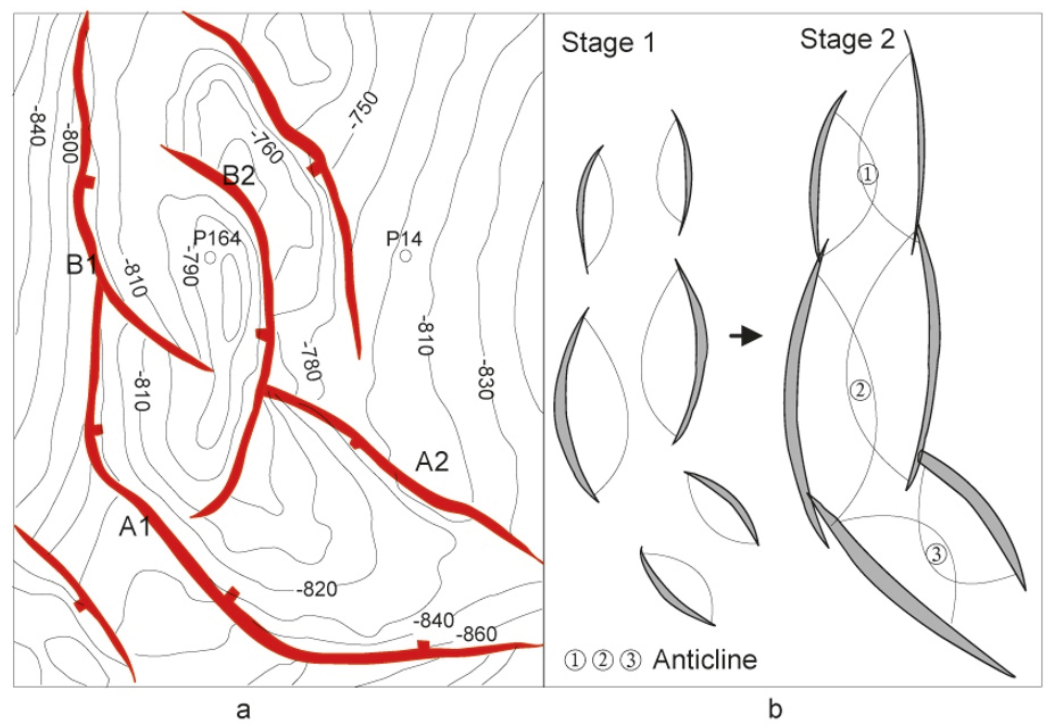

Fig. 4 Convergent accommodation zone on structural contour map top of Putaohua reservoir and its evolution model

a: An anticline belt is formed between two groups of faults dipping toward each other. b: Stage 1, individual fault; stage2, faults interact with each other in the direction both parallel and vertical to the strike.

\subsubsection{Divergent accommodation zone model}

What discussed above is the geometry and development of the hanging wall of faults when they approach and overlap. When two faults with opposite dip directions grow laterally, they gradually overlap and become parallel. Their common footwall is uplifted because of isostatic effect, and a horst is produced on the footwall (Faulds and Varga, 1998), whereas their hanging walls subside, forming two half-grabens on them. Many traps in the study area result from this kind of origin, and can be subdivided into two types according to the extent of fault overlap and fault size. If two faults overlap partly, the uplift of the footwall is relatively low (Fig. 5(a)). If the faults continue to grow laterally until they completely overlap, the uplift of the zone is very high (Fig. 5(b)), and the zone becomes a favorable trap for hydrocarbon.

\section{Hydrocarbon migration and accumulation model}

Clastic deposition in the hydrocarbon-generating zone (Putaohua reservoir) is characterized by thick shale of lacustrine and delta front facies interspersed with much thinner and laterally sparse sand bodies with the ratio of sand/shale less than $16 \%$. The thick source rock of the Qingshankou Formation lies under the reservoir formation. The most crucial factors for hydrocarbon accumulation are vertical migration through faults offsetting source rock to reservoir formation and lateral migration mainly through sand bodies. The former provides the pathways from source rock to reservoir formation, and the latter determines the hydrocarbon accumulation. Consequently, fault-related traps are advantageous to capturing hydrocarbon.

Most of faults in the study area are syndepositional, with thicker sand on hanging walls. Highly porous or permeable sand bodies and fault surface are the main migration pathways of oil and gas, but the permeability allowing fluid migration on a large fault surface is heterogeneous (Hindle, 1997). Faults are not only the pathways but also barriers for hydrocarbon migration, which mostly depends on the activity of faults. Generally, the moving faults or their active segments are favorable pathways for hydrocarbon migration and the nonmoving faults may probably be barriers (Wang et al, 1994). According to the normal fault growth model, it is known that the displacement of a fault reaches a maximum near its center, which coincides with the stretch extent of fault, and decreases toward both tips. This reveals that the vertical hydrocarbon migration of traps related to faults is mainly through the center of faults in the fault evolution stage 1 and 2. For synthetic fault genetic traps, hydrocarbon enters the thick sand bodies of the hanging wall which is the lowest point of the graben, then migrates laterally to the intra-graben high on the linkage. In the stage of fault connection, the maximum displacement (stretch extent) transfers to the area of fault linkage, and so do the migration pathways (Fig. 6(a)). Obviously the intra-graben highs are always favorable targets for hydrocarbon migration. For the convergent zones, hydrocarbon migrates vertically at the position of maximum fault displacement where the anticlines between bounding faults are relatively low, and then 


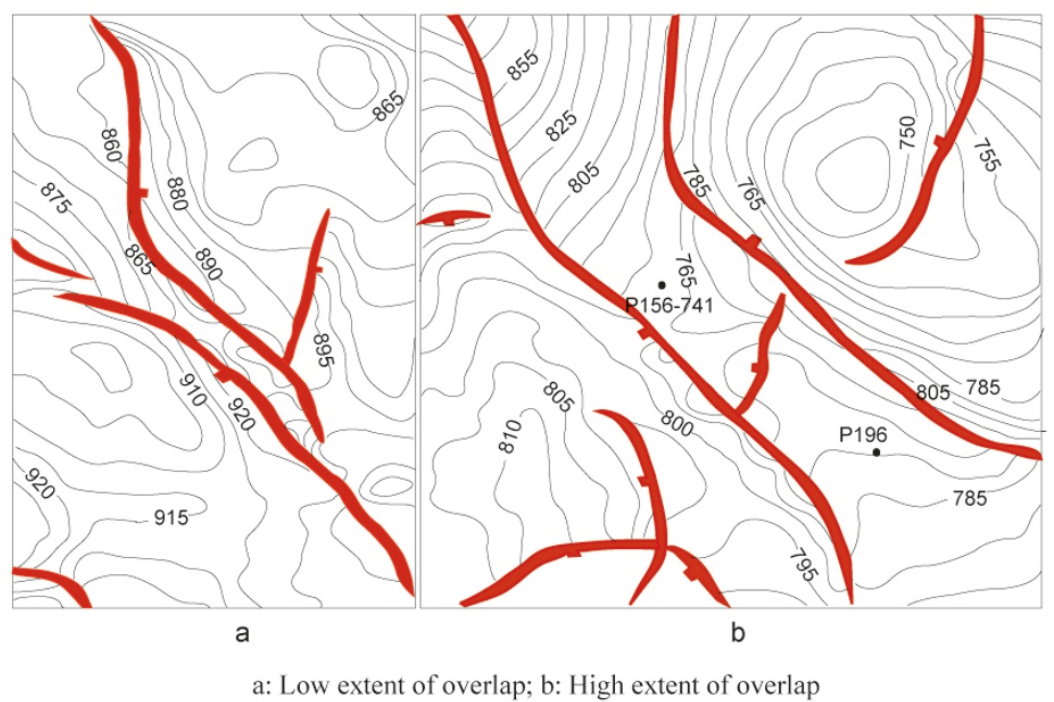

Fig. 5 Divergent accommodation zone in Putaohua reservoir
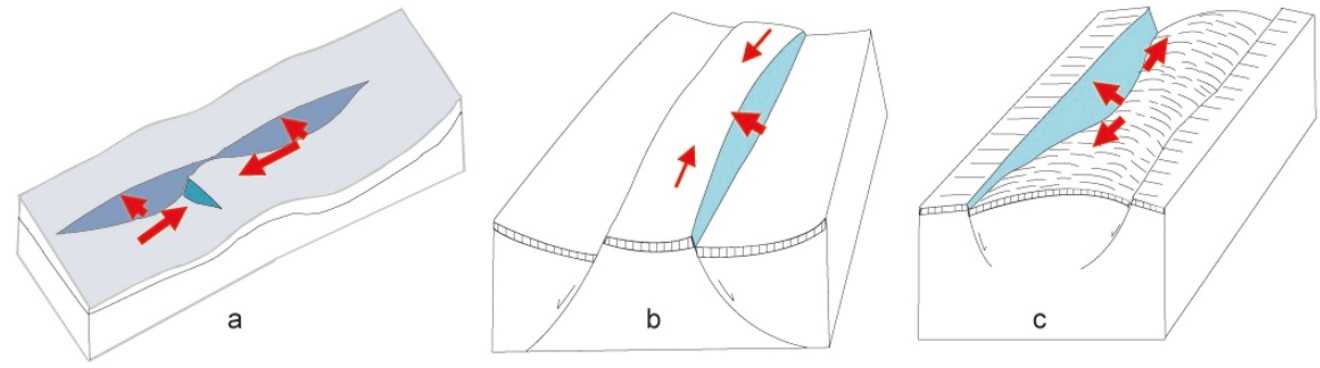

$\rightarrow$ Favorable hydrocarbon migration

a: Synthetic accommodation zone; b: Convergent accommodation zone; c: Divergent accommodation zone

Fig. 6 Hydrocarbon migration and accumulation models related to fault growth in Putaohua reservoir

migrates laterally to highs (Fig. 6(b)). For the divergent zones, hydrocarbon from vertical migration may enter footwall highs directly, which always coincide with the half-grabens on the hanging wall in the fault growth stage 1 and 3, but in stage 2, vertical migration takes place in the area of fault linkage, then hydrocarbon migrates laterally into uplifts of the footwalls (Fig. 6(c)).

Consequently, normal fault-related traps are favorable to capturing hydrocarbon, especially the traps on hanging wall. It is because most of the faults are syndepositional with thick sand bodies on the hanging wall in the study area, which benefits the lateral hydrocarbon migration and accumulation.

\section{Conclusions}

Structural traps in Putaohua oilfield are closely related to normal faults, and their genetic models can be divided into two types: individual normal fault model and multi-fault interaction model.

1) Individual normal fault model: The displacement of normal fault reaches a maximum in or near the center of the fault, decreases toward the fault tips, and produce a half-graben on the hanging wall and a half-anticline on the footwall because of the isostatic process. Half-grabens are often highly water-flooded, but uplifts are favorable for enrichment of remaining oil in the middle or late stages of oil production.

2) Accommodation zone by fault interaction genetic model: the individual normal fault model occurs at the beginning of fault development. When faults grow, they interact with others because of the increase of displacement, and produce accommodation zones between overlapping segments. The accommodation zones are favorable structural traps for hydrocarbon, and their geometries are dependent on the extent of overlap and occurrence of faults.

3) The faults are the main pathways linking the source rock and the reservoir formation, but they play different roles because of the different occurrences of faults. In different fault development stages, structural traps of different genetic models have their own characteristics of hydrocarbon migration and accumulation.

\section{Acknowledgements}

This work was supported by the National Natural Science Foundation of China (Project No.40372072). 


\section{References}

Anders M H and Schlische R W. Overlapping faults, intrabasin highs and the growth of normal faults. Journal of Geology. 1994. 102(2): $165-180$

Bonson C G, Childs C, Walsh J J, et al. Geometric and kinematic controls on the internal structure of a large normal fault in massive limestones: The Maghlaq Fault, Malta. Journal of Structural Geology. 2007. 29(2): 336-354

Cowie P A and Scholz C H. Growth of faults by accumulation of seismic slip. Journal of Geophysical Research. 1992. 97(B7): 11085-11095

Densmore A L, Dawers N H, Gupta S, et al. What sets topographic relief in extensional footwalls? Geology. 2005. 33(6): 453-456

Dula W F. Geometric models of listric normal faults and rollover folds. AAPG Bulletin. 1991. 75(10): 1609-1625

Faulds J E and Varga R J. The role of accommodation zones and transfer zones in the regional segmentation of extended terranes. Geological Society of America Special Paper. 1998. 323: 1-45

Ford M, de Veslud C Le C and Bourgeois O. Kinematic and geometric analysis of fault-related folds in a rift setting: The Dannemarie Basin, Upper Rhine Graben, France. Journal of Structural Geology. 2007. 29(11): 1811-1830

Hindle A D. Petroleum migration pathways and charge concentration: a three-dimensional model. AAPG Bulletin. 1997. 81(9): 1451-1481

Kim Y S and Sanderson D J. The relationship between displacement and length of faults: a review. Earth-Science Reviews. 2005. 68(3-4): 317-334

Li X. Model for hydrocarbon accumulation of Dongxin Oil Field in the Dongying Sag. Journal of Basic Science and Engineering. 2004. 12(2): 169-178 (in Chinese)

Morley C K, Nelson R A, Patton T L, et al. Transfer zones in East African Rift system and their relevance to hydrocarbon exploration in rifts. AAPG Bulletin. 1990. 74(8): 1234-1253

Rosendahl B R. Architecture of continental rifts with special reference to East Africa. Annual Review of Earth and Planetary Sciences. 1987. 15: $445-503$

Scott D L and Rosendahl B R. North Viking Graben: an East African perspective. AAPG Bulletin. 1989. 73(2): 155-165

Shelton J W. Listric normal faults: an illustrated summary. AAPG Bulletin. 1984. 68(7): 801-815

Soliva R and Benedicto A. Geometry, scaling relations and spacing of vertically restricted normal faults. Journal of Structural Geology. 2005. 27(2): 317-325

Varga R J, Faulds J E, Snee L W, et al. Miocene extension and extensional folding in an anticlinal segment of the Black Mountains accommodation zone, Colorado River extensional corridor, southwestern United States. Tectonics. 2004. 23(1): 1-19

Walsh J J and Watterson J. Analysis of the relationship between displacement and dimensions of faults. Journal of Structural Geology. 1988. 10: 239-247

Wang P, Li J F and Li Y Q. Fine exploration and development of complex fault-blocks. Beijing: Petroleum Industry Press. 1994. 6 (in Chinese)

Wang Y K. Preliminary investigation on the geological features and oil bearing regularity of Dongxin Oil Field in Shengli oil area. Journal of Xi'an Petroleum Institute. 1995. 10(1): 18-20 (in Chinese)

Watterson J. Fault dimensions, displacements and growth. Pure and Applied Geophysics. 1986. 124(1-2): 365-373

Xiao H B and Suppe J. Origin of rollover. AAPG Bulletin. 1992. 76(4): 509-529

Xie X Y, Deng J G and Xin Q L. Fault-block models and hydrocarbon accumulation in Dongxin Oilfield. Petroleum Exploration and Development. 1997. 24(2): 25-27 (in Chinese)

(Edited by Hao Jie) 